\title{
Specialization of the paralogue LYS21 determines lysine biosynthesis under respiratory metabolism in Saccharomyces cerevisiae
}

Correspondence

Alicia González

amanjarr@ifc.unam.mx

Received 24 January 2008

Revised 3 March 2008

Accepted 7 March 2008
Héctor Quezada, ${ }^{1}$ Cristina Aranda, ${ }^{1}$ Alexander DeLuna, ${ }^{1}$ Hugo Hernández, ${ }^{1}$ Mario L. Calcagno, ${ }^{2}$ Álvaro Marín-Hernández ${ }^{3}$ and Alicia González ${ }^{1}$

\begin{abstract}
${ }^{1}$ Departamento de Genética Molecular, Instituto de Fisiología Celular, Universidad Nacional Autónoma de México, Apartado Postal 70-242, México DF 04510, México

${ }^{2}$ Laboratorio de Fisicoquímica e Ingeniería de Proteínas, Departamento de Bioquímica, Facultad de Medicina, Universidad Nacional Autónoma de México, México DF 04510, México

${ }^{3}$ Instituto Nacional de Cardiología, Departamento de Bioquímica, Tlalpan, México DF, México
\end{abstract}

\begin{abstract}
In the yeast Saccharomyces cerevisiae, the first committed step of the lysine biosynthetic pathway is catalysed by two homocitrate synthases encoded by $L Y S 20$ and $L Y S 21$. We undertook a study of the duplicate homocitrate synthases to analyse whether their retention and presumable specialization have affected the efficiency of lysine biosynthesis in yeast. Our results show that during growth on ethanol, homocitrate is mainly synthesized through Lys21p, while under fermentative metabolism, Lys20p and Lys21p play redundant roles. Furthermore, results presented in this paper indicate that, in contrast to that which had been found for Lys20p, lysine is a strong allosteric inhibitor of Lys21p $\left(K_{\mathrm{i}} 0.053 \mathrm{mM}\right)$, which, in addition, induces positive cooperativity for $\alpha$-ketoglutarate ( $\alpha-K G$ ) binding. Differential lysine inhibition and modulation by $\alpha-K G$ of the two isozymes, and the regulation of the intracellular amount of the two isoforms, give rise to an exquisite regulatory system, which balances the rate at which $\alpha-K G$ is diverted to lysine biosynthesis or to other metabolic pathways. It can thus be concluded that retention and further biochemical specialization of the LYS20- and LYS21-encoded enzymes with partially overlapping roles contributed to the acquisition of facultative metabolism.
\end{abstract}

\section{INTRODUCTION}

In the yeast Saccharomyces cerevisiae, lysine is synthesized through the $\alpha$-amino adipate (AAA) pathway (Nishida \& Nishiyama, 2000). Although the first steps of this pathway are fairly distributed among different phylogenetic groups of microorganisms (Kosuge \& Hoshino, 1998; Nishida et al., 1999), the LYS2-encoded AAA reductase is exclusive to fungi and is considered to be the hallmark enzyme of fungal lysine biosynthesis (Nishida \& Nishiyama, 2000). Seven enzymes, eight steps, and more than 12 unlinked genes are responsible for the biosynthesis of lysine in $S$. cerevisiae. This amino acid, which is preferentially located in the vacuole, and cannot be used as nitrogen or carbon source (Watson, 1976), plays an important physiological role, contributing to the build-up of the stress response provoked by $\mathrm{H}_{2} \mathrm{O}_{2}$ treatment (Stephen \& Jamieson, 1997), prevention of amino acid starvation-induced apoptosis

Abbreviations: AAA, $\alpha$-amino adipate; $\alpha$-AASA, 2-aminoadipate semialdehyde; AcCoA, acetyl CoA; DCIP, 2,6-dichloroindophenol; $\alpha-K G$, $\alpha$-ketoglutarate.
(Eisler et al., 2004), and cryoprotection (Takagi et al., 1997).

The first committed step in lysine biosynthesis takes place in the nucleus (Chen et al., 1997) and is catalysed by the homocitrate synthase (formerly EC 4.1.3.21, now EC 2.3.3.14), which condenses acetyl CoA (AcCoA) with $\alpha$ ketoglutarate $(\alpha-K G)$ to yield homocitrate and CoA. Subsequent steps of the pathway are localized in the mitochondrion and the cytosol (Betterton et al., 1968). This reaction is highly regulated and is thought to be the rate-limiting step of the pathway (Xu et al., 2006). In S. cerevisiae, two homocitrate synthase isozymes encoded by LYS20 and LYS21, $92 \%$ identical in amino acid sequence, are responsible for this activity (Feller et al., 1999). These genes are located on different regions of chromosome IV and belong to the group of gene pairs that were selectively conserved after the entire duplication of the yeast genome (Wolfe \& Shields, 1997).

Upon amino acid deprivation, expression of both LYS20 and LYS21 is induced through the action of Gcn $4 p$ 
(Natarajan et al., 2001). Positive regulation of both genes is also achieved by Lys14p, a transcriptional activator of the Zn-Cys cluster family, which requires 2-aminoadipate semialdehyde ( $\alpha$-AASA) as a co-inducer (Ramos et al., 1988). In addition, LYS20 and LYS21 are positively coregulated by the target of rapamycin (TOR) signalling pathway coupled with protein kinase A, through a LYS14GCN4-independent pathway (Chen \& Powers, 2006). Lysine repression occurs as this amino acid counteracts expression activation through Lys14p and $\alpha$-AASA (Feller et al., 1994); repression is simultaneously abolished in mutant strains impaired in lysine-mediated feedback inhibition (Feller et al., 1999).

$S$. cerevisiae is able to grow under fermentative and respiratory conditions using a variety of carbon sources. Interestingly, the whole genome-duplication event shows a strong correlation with the appearance of fermentative lifestyles in the Saccharomyces lineage (Merico et al., 2007). It has been proposed that the selective conservation of certain duplicates could have enhanced the acquisition of facultative metabolic properties (Piskur, 2001). In particular, it has been proposed that the conservation of the paralogous pair GDH1 and GDH3 contributes to the mechanisms allowing $\alpha$-KG utilization without impairing the integrity of the tricarboxylic acid cycle as an energyproviding system. It has been shown that the existence of two NADP-glutamate dehydrogenase isozymes allows the functioning of a regulatory system in which the relative abundance of each isoform modulates the rate at which $\alpha$ KG is channelled to glutamate biosynthesis (Avendaño et al., 2005; DeLuna et al., 2001). Considering that the LYS20and LYS21-encoded isozymes are involved in $\alpha-K G$ and AcCoA utilization, specialization of these genes could have led to the acquisition of kinetic properties that endow Lys $20 \mathrm{p}$ and Lys $21 \mathrm{p}$ with a relevant regulatory role in the differential utilization of carbon intermediates under fermentative or respiratory metabolism.

Results presented in this paper show that LYS20 and LYS21 have been retained to increase gene dosage under fermentative conditions, and that biochemical specialization of these isozymes has led to modulation of the homocitrate synthase activity, allowing balanced lysine biosynthesis and $\alpha$-KG utilization during growth by respiration of less favourable carbon sources.

\section{METHODS}

Strains. Table 1 describes the characteristics of the strains used in the present work. All strains constructed for this study were LEU2 derivatives of CLA1 (ura3 leu2), and thus suited for URA3 selection. To obtain strain CLA1-2 (ura3 leu2:: LEU2), CLA1 was transformed with the $1989 \mathrm{bp}$ PCR product of primers Leu2Fo (5'-GAC CGC AGT TAA CTG TGG-3') and Leu2Re (5'-CGA CTA CGT CGT TAA GGC-3'), which contains the LEU2 gene under the control of its native promoter. Genomic DNA from strain S288C was used as a template, and transformants were selected for leucine prototrophy. To obtain a lys20D mutant strain (CLA1-2-21), CLA1-2 was transformed with a 2675 bp PCR product containing the kanMX4
Table 1. Strains used in this study

\begin{tabular}{|c|c|}
\hline Strain & Genotype \\
\hline CLA1-2 & MAT $\alpha$ LYS20 LYS21 ura3 leu2:: LEU2 \\
\hline CLA1-2-21 & MAT $\alpha$ lys20D:: kanMX4 LYS21 ura3 leu2:: LEU2 \\
\hline CLA1-2-20 & 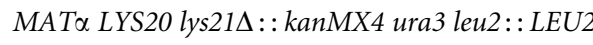 \\
\hline CLA1-2C & CLA1-2/pRS316 (CEN URA3) \\
\hline CLA1-2-20C1 & CLA1-2-20/pMON21(LYS21 CEN URA3) \\
\hline CLA1-D & 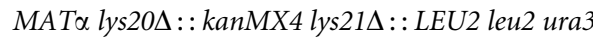 \\
\hline CLA1-2M & 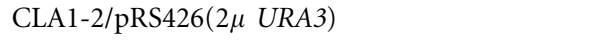 \\
\hline CLA1-DM & CLA1-D/pRS426 ( $2 \mu$ URA3) \\
\hline CLA1-D-21M & CLA1-D/pMUL21 (LYS21 $2 \mu$ URA3) \\
\hline CLA1-D-20M & CLA1-D/pMUL20 (LYS20 $2 \mu$ URA3) \\
\hline CLA1-D-Q10 & CLA1-D/pMULQ10 (5'LYS21-LYS20 $2 \mu$ URA3) \\
\hline
\end{tabular}

cassette, and LYS20 upstream (987 bp) and downstream (182 bp) nucleotide sequences amplified from genomic DNA of the Euroscarf collection strain Y33880 using the deoxyoligonucleotides LYS20Fo (5'-TAC TGC GTG CGC TTG AGA TTC AG-3') and LYS20Re (5'TCC CCT TAT TCT GCC GCG AAT G-3') and selecting for G418 (200 mg $1^{-1}$; Life Technologies) resistance. To obtain a lys $21 \Delta$ mutant, CLA1-2 was transformed with a 2395 bp PCR product containing the kanMX4 cassette, and LYS21 upstream (640 bp) and downstream (249 bp) nucleotide sequences amplified from genomic DNA of the Euroscarf collection strain Y33828, using deoxyoligonucleotides L1F2 (5'-CAT CTT TGA AGG CTT GTG CTG ATC- ${ }^{\prime}$ ) and L1R2 (5'-CTC CGT GAG AGT ATA ATA GCG TG-3'), generating the strain CLA1-2-20. Single mutants were verified by amplifying the kanMX4 cassette with the flanking regions and digesting it with BamHI, which digests the kanMX4 cassette but not the wild-type genes; genomic DNA from the G418-resistant colonies was used as a template using the deoxyoligonucleotides described above. The double mutant CLA1-D was constructed by interrupting the LYS20 gene with kanMX4 and LYS21 with LEU2 as follows: the LEU2 gene was PCR-amplified using the deoxyoligonucleotides LYS21LEU2Fo (5'- GCG CGC TGA TCA GAC CGC AGT TAA CTG TGG-3') and LYS21LEU2Re (5' - GCG CGC TGA TCA CGA CTA CGT CGT TAA GGC-3'). Genomic DNA from the S288C wild-type strain was used as a template. Cohesive ends were generated by digesting with $B c l$ at the recognition site indicated in bold type; once purified, this DNA was ligated to the gel-purified $4731 \mathrm{bp}$ product from $B c$ II digestion of LYS21 cloned into the pGEM-T Easy Vector (Promega). The lys $21 \Delta$ : :LEU2 construct was then PCR-amplified with the L1F2 and L1R2 deoxyoligonucleotides, producing a 3720 bp DNA fragment which was transformed into the CLA1 strain. Transformants were selected for leucine prototrophy and the interruption was verified by PCR; a $3720 \mathrm{bp}$ product susceptible to KpnI digestion indicated correct interruption. These strains were transformed with the lys20D:: kanMX4 cassette obtained from strain Y33880 as described above, and then selected for G418 resistance; the insertion was verified as described for the CLA1-2-21 strain.

Yeast was transformed following the method described by Ito et al. (1983). Transformants were selected for either leucine prototrophy on minimal medium (MM), or G418 (200 $\mathrm{mg} \mathrm{l}^{-1}$; Life Technologies) resistance on yeast extract-peptone-glucose (YPD) rich medium.

Growth conditions. Strains were routinely grown on MM containing salts, trace elements and vitamins, following the formula of yeast nitrogen base (Difco). Filter-sterilized glucose (2\%, w/v) or ethanol $(2 \%, \mathrm{v} / \mathrm{v})$ was used as carbon source, and $40 \mathrm{mM}$ ammonium sulfate was used as a nitrogen source. The volume of flasks was five times that of the medium. Supplements needed to satisfy auxotrophic require- 
ments were added at $20 \mathrm{mg} \mathrm{l}^{-1}$ for uracil and $30 \mathrm{mg} \mathrm{l}^{-1}$ for lysine. Cells were incubated at $30{ }^{\circ} \mathrm{C}$ with shaking (250 r.p.m.).

Construction of low-copy-number and high-copy-number plasmids bearing LYS20 or LYS21 genes. All standard molecular biology techniques were followed as described by Sambrook et al. (1989). LYS20 or LYS21 was PCR-amplified together with the respective $5^{\prime}$ promoter sequence and cloned into either the pRS316 (CEN6 ARSH4 URA3) low-copy-number or pRS426 ( $2 \mu$ ori URA3) high-copy-number plasmid (Sikorski \& Hieter, 1989; Christianson et al., 1992). For LYS20, a 2457 bp fragment was PCR-amplified using deoxyoligonucleotides LYS20Fo and LYS20Re with genomic DNA from strain BY4743. This DNA was cloned into the pGEM-T Easy Vector (Promega) and subcloned into NotI-digested pRS426, generating plasmid pMUL20 (LYS20 $2 \mu$ URA3), which was used to transform the double mutant CLA1-D, thus generating the LYS20overexpressing strain CLA1-D-20M. For LYS21, a 2212 bp fragment was PCR-amplified with the deoxyoligonucleotides L1F2 and L1R2 described above; this fragment was cloned into the pGEM-T Easy Vector (Promega) and subcloned into NotI-digested pRS426, generating plasmid pMUL21 (LYS21 $2 \mu$ URA3), or into XhoI-NotIdigested pRS316, generating plasmid pMON21 (LYS21 CEN URA3). The LYS21-overexpressing strain CLA1-D-21M was obtained by transforming the double mutant CLA1-D with pMUL21. The LYS21complemented strain CLA1-2-20C1 was obtained by transforming the lys21 single mutant (CLA1-2-20) with pMON21. Control strains CLA1-2M and CLA1-DM were constructed by transforming the wildtype CLA1-2 and the double mutant CLA1-D with pRS426; the CLA1-2C control strain was constructed by transforming wild-type CLA1-2 with plasmid pRS316. All transformants were selected for uracil prototrophy.

Construction of $L Y S 21$ and $L Y S 20$ chimerical fusion plasmids. To obtain the fusion containing the promoter sequence of LYS21 and the coding sequence of LYS20, an overlapping PCR amplification was performed. The LYS21 promoter was amplified with primers Q110PFo (5'-GAA CGA AGC AAA TCC TAC GAG TAA ATA CAT AAG- $3^{\prime}$ ) and Q110PURe (5'-ATT TGG TTT AGC AGC AGT CAT GGT TTG TTA AAG TAT ACA ATT ACT-3'); the $637 \mathrm{bp}$ product contained the $5^{\prime}$ cognate sequence and the first $21 \mathrm{bp}$ of the LYS20 coding sequence (indicated in bold type), and plasmid pMUL21 was used as a template. The $1469 \mathrm{bp}$ PCR product of primers Q110CFo (5'-GAC TGC TGC TAA ACC AAA TCC ATA TGC T-3') and LYS20Re comprised the LYS20 coding region and $182 \mathrm{bp}$ after the stop codon; the annealing temperature was $59{ }^{\circ} \mathrm{C}$, and plasmid pMUL20 was used as template. The overlapped amplification produced the $2085 \mathrm{bp}$ fusion and the reaction was carried out at an annealing temperature of $50{ }^{\circ} \mathrm{C}$. This PCR product was cloned into the pGEM-T Easy Vector (Promega) and subcloned into NotI-digested pRS426, generating plasmid pMULQ10 (5'LYS21LYS20 $2 \mu$ URA3), which was transformed into the double mutant CLA1-D to obtain strain CLA1-D-Q10.

Cell extract preparation and enzyme assay. Cells were cultured to exponential growth phase $\left[\mathrm{OD}_{600} 0.4-0.6\right.$ in a spectrophotometer (LKB Ultrospec III; Pharmacia) with $1 \mathrm{~cm}$ path length], harvested by centrifugation and washed with cold water. Extract preparation was performed following the protocol described by Ramos \& Wiame (1985). Enzymic activity was determined by the 2,6-dichloroindophenol (DCIP) colorimetric method described by Andi et al. (2004b), in a final volume of $0.5 \mathrm{ml} ; 50 \mathrm{mM}$ HEPES, $\mathrm{pH}$ 7.2, $0.1 \mathrm{mM}$ DCIP, $0.5 \mathrm{mM}$ AcCoA and $40 \mathrm{mM} \alpha-\mathrm{KG}$. All assays were performed at $30{ }^{\circ} \mathrm{C}$ in a Varian Cary 400 spectrophotometer with a $1 \mathrm{~cm}$ path length. After $5 \mathrm{~min}$ thermal equilibration and completion of the reaction provoked by the contaminant CoA present in the commercial AcCoA preparation with DCIP, the assay was started with dialysed cell-free extract $(0.2 \mathrm{mg}$ protein), and the initial reaction rate was obtained from the change in $\mathrm{OD}_{600}$. Protein was measured by the method of Lowry et al. (1951) and BSA as a standard.

\section{Preparation of a chromatographic fraction and stabilization of} Lys21p. Lys21p was obtained from MM-glucose-grown cultures of strain CLA1-D-21M. Cells were harvested by centrifugation when cultures reached an $\mathrm{OD}_{600}$ of 1.2-1.4; the cells were disrupted with glass beads. A $0.5 \mathrm{ml}$ volume of non-dialysed extract was used for gel filtration on a Superdex S-200 column $(15 \times 300 \mathrm{~mm}$; GE Healthcare Life Sciences) equilibrated with HEPES ( $50 \mathrm{mM}, \mathrm{pH} 7.2$, flowing at $\left.0.5 \mathrm{ml} \mathrm{min}^{-1}\right)$. Fractions with Lys $21 \mathrm{p}$ activity were mixed with an equal volume of $2 \mathrm{M}$ trehalose prepared in HEPES ( $50 \mathrm{mM}$, pH 7.2). In this solution, Lys $21 \mathrm{p}$ activity was constant for $24 \mathrm{~h}$ if maintained on ice; the protein concentration was $4 \mathrm{mg} \mathrm{ml}^{-1}$. Stabilization procedures described elsewhere for Lys20, based on the use of a combination of $100 \mathrm{mM} \alpha$-cyclodextrin, $600 \mathrm{mM}$ ammonium sulfate and $100 \mathrm{mM}$ guanidinum chloride as stabilizing agents (Andi et al., 2004b), did not allow Lys21p stabilization; this was achieved in the presence of $1 \mathrm{M}$ trehalose.

Enzyme kinetics and analysis of kinetic data. Homocitrate synthase activity was assayed using DCIP as an oxidant of the CoA produced in the reaction, as described by Andi et al. (2004b). The final volume of the assay was $0.5 \mathrm{ml}$ containing $50 \mathrm{mM}$ HEPES, $\mathrm{pH} 7.5,100 \mathrm{mM}$ trehalose, $0.1 \mathrm{mM}$ DCIP, and variable concentrations of $\alpha-\mathrm{KG}, \mathrm{AcCoA}$ and lysine. All assays were carried out at $30{ }^{\circ} \mathrm{C}$ in a Varian Cary 400 spectrophotometer with a $1 \mathrm{~cm}$ path length. The assay was started with $0.2 \mathrm{mg}$ protein. Initial velocity measurements, when $\alpha-K G$ was the varied substrate, were done at an AcCoA concentration of $0.2 \mathrm{mM}$. When AcCoA concentration was varied, $\alpha-$ $\mathrm{KG}$ was maintained at $50 \mathrm{mM}$. Kinetic data were analysed by nonlinear regression using the program Origin 7.0 (OriginLab).

Northern blot analysis. Northern analysis was carried out as described previously (Valenzuela et al., 2001). Total yeast RNA was prepared as described by Struhl \& Davis (1981) from exponentially grown cells $\left(\mathrm{OD}_{600} 0.4-0.6\right)$ in $100 \mathrm{ml}$ cultures. Given the high identity of LYS20 and LYS21, small radioactive PCR products near the stop codon were used as probes to reduce cross-hybridization. For LYS20, a 108 bp product was amplified with primers NLYS20Fo2 (5' GGT CAG CAC TCC TCA AGT AC-3') and NLYS20Re2 (5'-TAG GCG GAT GGC TTA GTC C-3'). For LYS21, a 107 bp PCR product was amplified with NLYS21Fo2 (5' -ATT GAG CAC CCC ACT TTT AAA ACC- $3^{\prime}$ ) and NLYS21Re2 (5'-GAA ACT ATT TGG TGA CCT TTG CC-3'). A BamHI-HindIII 1599 bp restriction fragment of $A C T 1$ was used as an internal loading standard. Blots were scanned using the program ImageQuant 5.2 (Molecular Dynamics).

Gel electrophoresis and immunoblotting. Protein extracts obtained from the pertinent strains were subjected to SDS-PAGE, performed with $10 \%$ slab gels, and transferred to nitrocellulose membranes. Incubation with antibodies was done as described elsewhere (Towbin et al., 1979). Mouse anti-yeast homocitrate synthase mAbs $31 \mathrm{~F} 5$ from EnCor Biotechnology were used at a dilution of $1: 200$. Peroxidase-conjugated anti-mouse antibodies were diluted $1: 1000$. Immunoblot signalling was optimized by analysing a number of combinations of antigen and antibody concentrations in the linear range of detectability.

Metabolite extraction and analysis. Cell-free extracts were prepared by quenching the cells in cold methanol, as described previously (González et al., 1997). Samples for intracellular lysine determination were deproteinized with perchloric acid. Intracellular lysine was determined by HPLC with an Ultrasphere ODS C18 column (Beckman Coulter) with ortho-phthalaldehyde (OPA) derivatization and a mobile phase of $75 \%$ methanol and $25 \%$ 
$0.1 \mathrm{M}$ potassium acetate buffer ( $\mathrm{pH} 5.5$ ) flowing at $1.5 \mathrm{ml} \mathrm{min} \mathrm{min}^{-1}$. Intracellular $\alpha$-KG was determined following the method described previously (González et al., 1997). For biomass determination, a dry weight calibration curve was produced for different optical densities.

\section{RESULTS}

\section{Under respiratory conditions, lack of LYS21 results in lysine bradytrophy}

To analyse the physiological role of Lys20p and Lys21p,

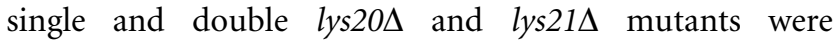

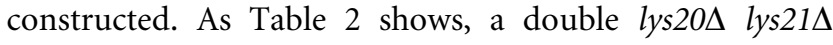
mutant displayed full lysine auxotrophy on both glucoseand ethanol-supplemented media. Both of the two single

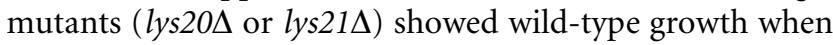
grown on MM supplemented with glucose as the carbon source (Table 2). Determination of the intracellular lysine pool showed that single mutant strains had a lysine content which was half that found in the wild-type strain (Fig. 1a). These results indicated that a wild-type growth rate on glucose could be maintained through the action of a single homocitrate synthase isozyme, although lysine biosynthesis was reduced. When single mutants were incubated with ethanol as the carbon source, growth of the lys20 $\Delta$ mutant was similar to that of the wild-type strain; however, a lack of LYS21 resulted in a diminished growth rate (Table 2). This effect was alleviated when lysine was added to the

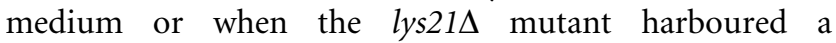
centromeric plasmid bearing LYS21 (Table 2). When growth rates of the wild-type and lys21s mutant were analysed using Student's $t$ test, a $P$ value of $1.3 \times 10^{-5}$ was obtained, indicating that the growth difference between the two strains was significant. Accordingly, the lys $21 \Delta$ mutant showed an almost threefold lower lysine pool as compared with that found in the wild-type strain, while the lysine

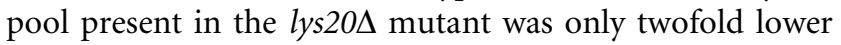
than that found in the reference strain (Fig. 1a). Student's $t$ test performed on the lysine pool values for the lys $20 \Delta$ and lys21s mutants confirmed that the difference in lysine pools between these two strains was significant $(P=0.001)$. It could thus be concluded that lack of Lys $21 \mathrm{p}$ resulted in lysine bradytrophy under respiratory conditions, which could not be compensated for by LYS20, suggesting that Lys $21 \mathrm{p}$ is the main contributor to the lysine pool under respiratory conditions.

\section{LYS21 expression is not induced under respiratory conditions}

To determine whether the role of Lys21p in ethanol-grown cultures was related to increased LYS21 expression under these conditions, its transcriptional regulation was analysed under fermentative and respiratory conditions. Northern blot analysis was carried out on total RNA extracted from exponentially grown cells on MM with glucose or ethanol as carbon sources. As Fig. 2(a) shows, LYS21 expression was similar on samples obtained from both glucose- and ethanol-grown cultures, in the wild-type and in the lys20D mutant strain background. Conversely, LYS20 expression was increased twofold when the wild-type strain was grown on ethanol as carbon source as compared with that found on glucose. In a lys21D background, LYS20 expression showed an additional increase, suggesting that expression of Lys 21 p represses LYS20 transcriptional activation. LYS20 expression showed a 33-fold increase when RNA was

\section{Table 2. Growth rates}

Cells were grown on minimal media with the indicated carbon source. Specific growth rate was determined during exponential phase. Values are presented as means \pm SD from three independent experiments.

\begin{tabular}{|c|c|c|}
\hline \multirow[t]{2}{*}{ Strain } & \multicolumn{2}{|c|}{ Specific growth rate $\left(h^{-1}\right)$} \\
\hline & Glucose & Ethanol \\
\hline CLA1-2 (LYS20 LYS21) & $0.305 \pm 0.019$ & $0.071 \pm 0.002$ \\
\hline CLA1-2-21 (lys20D LYS21) & $0.289 \pm 0.003$ & $0.069 \pm 0.003$ \\
\hline CLA1-2-20 (LYS20 lys21A) & $0.284 \pm 0.007$ & $0.060 \pm 0.003$ \\
\hline CLA1-2-20 (LYS20 lys $21 \Delta)+$ Lys $^{*}$ & $0.310 \pm 0.012$ & $0.073 \pm 0.002$ \\
\hline 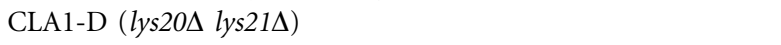 & 0 & 0 \\
\hline CLA1-D $(l y s 20 \Delta$ lys $21 \Delta)+$ Lys $^{*}$ & $0.296 \pm 0.008$ & $0.071 \pm 0.003$ \\
\hline CLA1-2C [CLA1-2/pRS316 (CEN URA3)] & $0.229 \pm 0.008$ & $0.075 \pm 0.004$ \\
\hline CLA1-2-20C1 [CLA1-2-20/pMON21 (LYS21 CEN URA3)] & $0.238 \pm 0.004$ & $0.071 \pm 0.005$ \\
\hline CLA1-2M [CLA1-2/pRS426 ( $2 \mu$ URA3)] & $0.233 \pm 0.001$ & $0.068 \pm 0.003$ \\
\hline CLA1-D-21M [CLA1-D/pMUL21 (LYS21 $2 \mu$ URA3)] & $0.235 \pm 0.003$ & $0.059 \pm 0.004$ \\
\hline CLA1-D-20M [CLA1-D/pMUL20 (LYS20 $2 \mu$ URA3)] & $0.221 \pm 0.002$ & $0.049 \pm 0.004$ \\
\hline CLA1-D-21M [CLA1-D/pMUL21 (LYS21 $2 \mu$ URA3)]+Lys* & $0.239 \pm 0.004$ & $0.069 \pm 0.007$ \\
\hline CLA1-D-20M [CLA1-D/pMUL20 (LYS20 $2 \mu$ URA3)] + Lys* & $0.245 \pm 0.004$ & $0.066 \pm 0.003$ \\
\hline CLA1-D-Q10 [CLA1-D/pMULQ10 (5'LYS21-LYS20 $2 \mu$ URA3)] & $0.219 \pm 0.006$ & $0.050 \pm 0.002$ \\
\hline
\end{tabular}

*The medium was supplemented with $30 \mathrm{mg}$ lysine $1^{-1}$. 

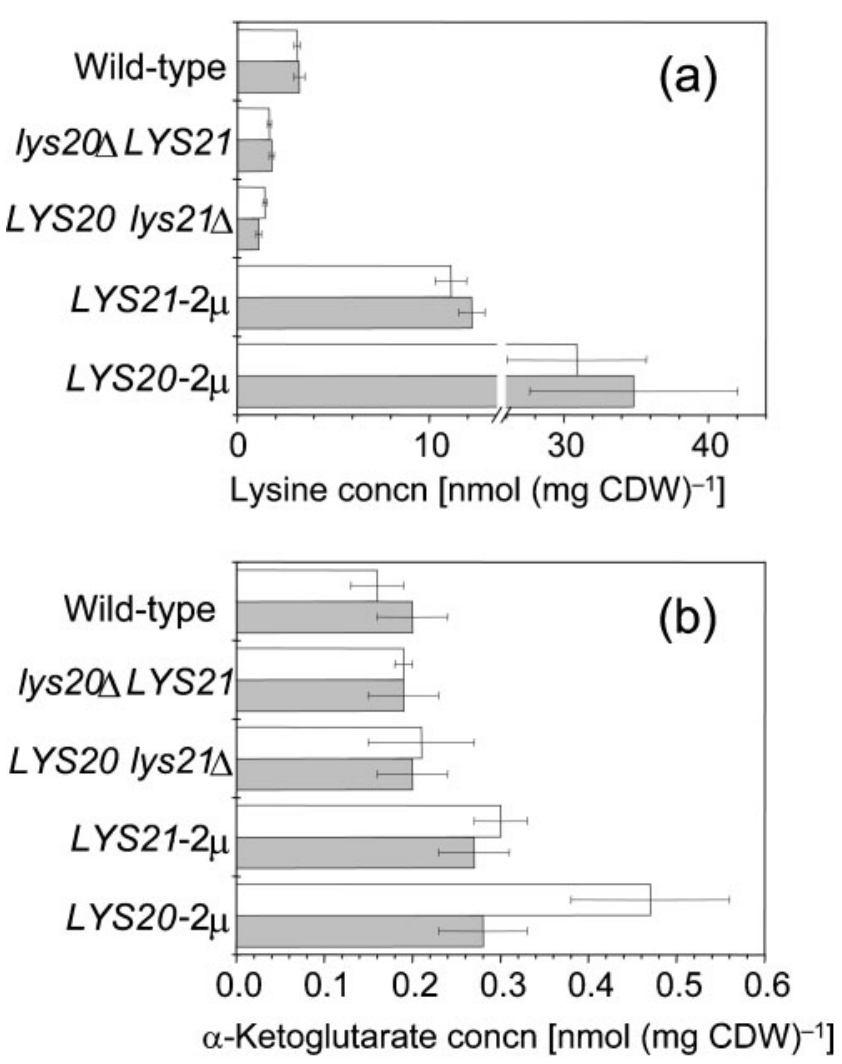

Fig. 1. Intracellular concentration of lysine and $\alpha-K G$ in extracts obtained from glucose- or ethanol-grown cells. Yeast cells were grown on MM supplemented with glucose (white bars) or ethanol (grey bars) and harvested during exponential growth. Cell-free extracts were prepared as described in Methods. (a) Lysine concentration; (b) $\alpha-K G$ concentration. Values for intracellular metabolites are relative to cell dry weight (CDW) and are presented as mean $\pm S D$ of three independent experiments. Strains used were: CLA1-2 (wild-type), CLA1-2-21 (lys20A

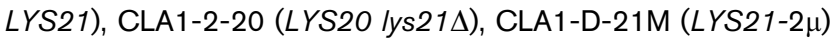
and CLA1-D-20M (LYS2O-2 $\mu)$.

prepared from glucose-grown cells harbouring LYS20 on a multicopy plasmid, as compared with expression in a wildtype strain (Fig. 2b), suggesting that when LYS20 is overexpressed, the increased lysine pool would depend on the production of a high $\alpha$-AASA pool that could result in Lys $14 \mathrm{p}$-mediated transcriptional activation. When RNA was prepared from ethanol-grown cells, LYS20 expression was 72 -fold higher as compared with that found in the glucose-grown wild-type strain (Fig. 2b), confirming that LYS20 expression is induced under respiratory conditions. Overexpression of LYS21 resulted in only a twofold increase in transcript content on glucose, in agreement with the fact that Lys $21 \mathrm{p}$ sensitivity to lysine would prevent excessive $\alpha$-AASA accumulation and Lys14p-dependent transcriptional activation. When RNA was extracted from ethanol-grown cultures, LYS21 expression attained sevenfold derepression as compared with that found in the wild-type strain grown on glucose or ethanol. Thus, increased expression of LYS21 in ethanol was only observed when this gene was present on a multicopy plasmid, suggesting that ethanol-dependent induction of LYS21 was small and was only amplified when the gene was present at a higher dose. It can thus be concluded that LYS21 expression is not significantly affected by the nature of the carbon source, while that of LYS2O is upregulated when ethanol is used as the sole carbon source. These results apparently contradict the observations presented above that indicate that Lys21p plays a major role in lysine biosynthesis under respiratory conditions, and hence that increased LYS21 expression could be expected under respiratory conditions. To further analyse this matter, homocitrate synthase activity in extracts obtained from the pertinent strains grown under fermentative or respiratory conditions was determined.

\section{Lys21p is the predominant isoform under respiratory conditions}

Homocitrate synthase enzymic activity was assayed in extracts obtained from exponentially grown cultures incubated on either glucose or ethanol as carbon source. As Table 3 shows, extracts from the wild-type strain obtained from either glucose- or ethanol-grown cells displayed similar specific activity, indicating that increased LYS20 expression on ethanol did not correspond to increased activity in the wild-type strain. Determination of homocitrate synthase activity in extracts obtained from glucose-grown cells showed that lack of either Lys21p or Lys $20 \mathrm{p}$ resulted in a similar decrease in homocitrate synthase specific activity as compared with that found in the wild-type strain. The differential contribution of Lys $20 \mathrm{p}$ and Lys $21 \mathrm{p}$ to homocitrate synthase activity was evidenced when activity was determined in extracts

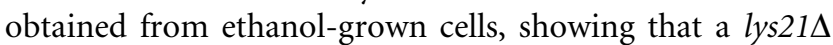
mutant only retained $25 \%$ of the wild-type activity, while a lys $20 \Delta$ mutant retained $70 \%$. This indicates that under respiratory conditions Lys $21 \mathrm{p}$ constitutes the major isoform, suggesting that this enzyme could play a critical role in lysine biosynthesis under respiratory conditions (Table 3).

LYS21 overexpression resulted in a 2.5 -fold increased enzymic activity on both glucose and ethanol as compared with the wild-type strain, thus the sevenfold increased transcription of LYS21 on ethanol did not result in a correspondingly increased enzymic activity. Similarly, overexpression of LYS20 from either its own promoter or the LYS21 promoter region resulted in a three- to fourfold increase in activity in extracts obtained from cultures grown on either glucose- or ethanol-supplemented media as compared with that found in the lys21 $1 \Delta$ mutant, which could suggest a gene dose effect. However, the 33- and 72fold increase in LYS20 expression observed on glucose and ethanol, respectively, as compared with that of the wildtype strain grown on glucose, was not correlated with a 

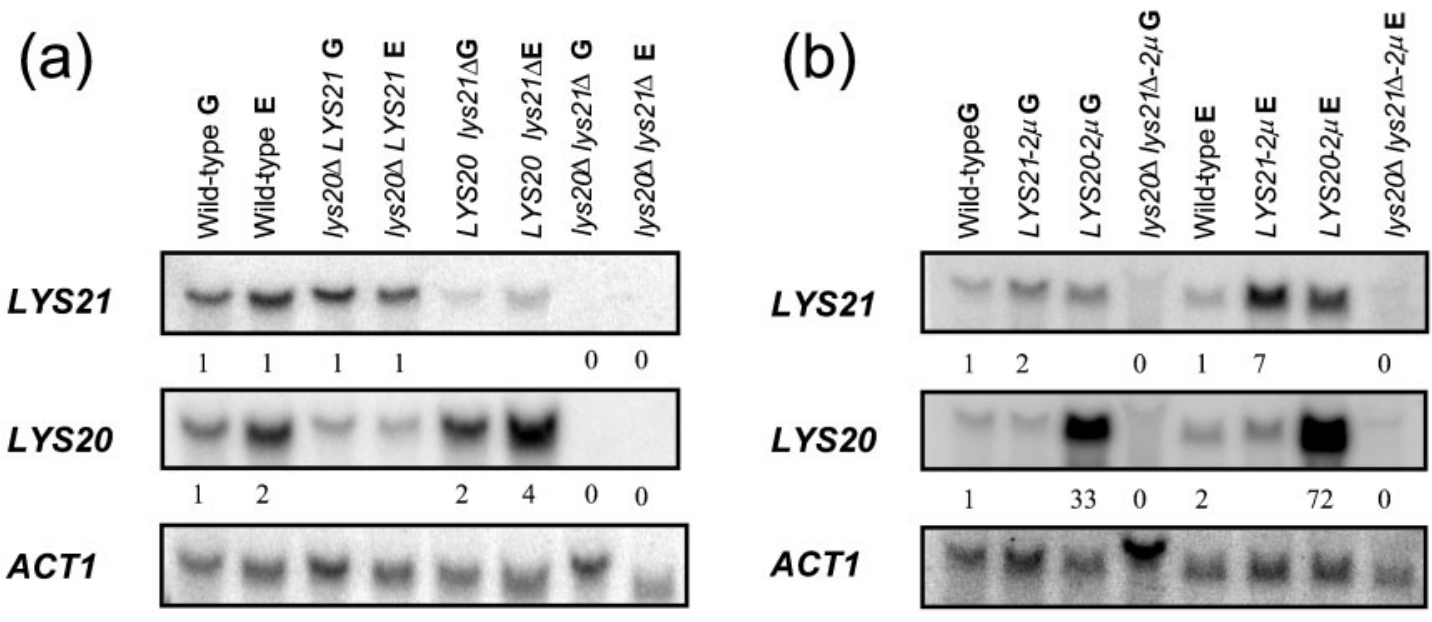

Fig. 2. LYS20 expression is induced under respiratory conditions. Northern analysis was carried out on total RNA obtained from the wild-type and mutant strains carrying single or double lys $20 \Delta$ or lys21D mutations (a), and from the double mutant

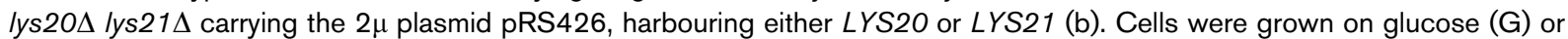

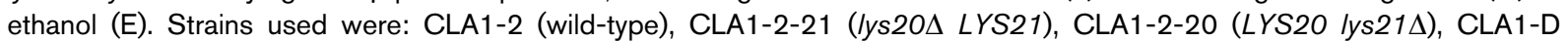

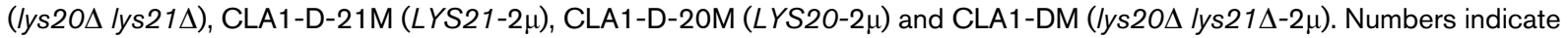
relative expression, as compared with the wild-type strain grown on glucose. Lanes without numbers indicate crosshybridization. Filters were sequentially probed with the LYS20- or LYS21-specific PCR products described in Methods. A BamHI-Hindlll 1500 bp ACT1 DNA fragment was used as a loading control. Four biological replicates were performed, and the results of representative experiments are shown.

corresponding increment in enzymic activity, suggesting that a post-transcriptional control limited LYS2O mRNA translation or Lys20p activity. Ethanol-induced expression of LYS21 did not result in increased enzymic activity, suggesting that Lys $21 \mathrm{p}$ could also be modulated by a posttranscriptional mechanism, but to a lesser extent than Lys20p, since Lys $21 \mathrm{p}$ specific activity on glucose was similar to that found on ethanol, while that of Lys20p invariably decreased on ethanol.
To determine the relative abundance of Lys $20 \mathrm{p}$ and Lys $21 \mathrm{p}$, Western blot analysis was carried out. As shown in Fig. 3 (a), lanes carrying extracts from the LYS20 lys $21 \Delta$ mutant were loaded with an amount of protein that was sixfold higher than that used for the wild-type and lys20D LYS21 mutant strains. A similar amount of Lys $21 \mathrm{p}$ was detected when extracts were prepared from the lys200 mutant grown on either glucose or ethanol (Fig. 3a). However, a smaller amount of Lys20p antigen as compared with that

Table 3. Homocitrate synthase specific activities

Cells were grown on minimal medium with the indicated carbon source and harvested during exponential growth $\left(\mathrm{OD}_{600}=0.4-0.6\right)$. Values are presented as means $\pm \mathrm{SD}$ from three independent experiments. ND, Not detected.

\begin{tabular}{|c|c|c|}
\hline \multirow[t]{2}{*}{ Strain } & \multicolumn{2}{|c|}{$\begin{array}{c}\text { Specific activity } \\
{\left[\mathrm{nmol} \mathrm{h}^{-1}\left(\mathrm{mg} \mathrm{protein}^{-1}\right)\right]}\end{array}$} \\
\hline & Glucose & Ethanol \\
\hline CLA1-2 (LYS20 LYS21) & $162 \pm 12$ & $198 \pm 18$ \\
\hline CLA1-2-21 (lys20D LYS21) & $114 \pm 12$ & $138 \pm 12$ \\
\hline CLA1-2-20 (LYS20 lys21D) & $84 \pm 12$ & $49 \pm 6$ \\
\hline CLA1-2C [CLA1-2/pRS316 (CEN URA3)] & $150 \pm 12$ & $186 \pm 18$ \\
\hline CLA1-2-20C1 [CLA1-2-20/pMON21 (LYS21 CEN URA3)] & $204 \pm 18$ & $192 \pm 12$ \\
\hline 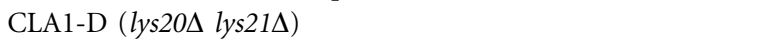 & $\mathrm{ND}$ & $\mathrm{ND}$ \\
\hline CLA1-2M [CLA1-2/pRS426 ( $2 \mu$ URA3)] & $150 \pm 12$ & $192 \pm 18$ \\
\hline CLA1-D-21M [CLA1-D/pMUL21 (LYS21 $2 \mu$ URA3)] & $414 \pm 42$ & $456 \pm 42$ \\
\hline CLA1-D-20M [CLA1-D/pMUL20 ( LYS20 $2 \mu$ URA3)] & $259 \pm 24$ & $185 \pm 9$ \\
\hline CLA1-D-Q10 [CLA1-D/pMULQ10 (5'LYS21-LYS20 2 $\mu$ URA3)] & $229 \pm 23$ & $163 \pm 17$ \\
\hline
\end{tabular}



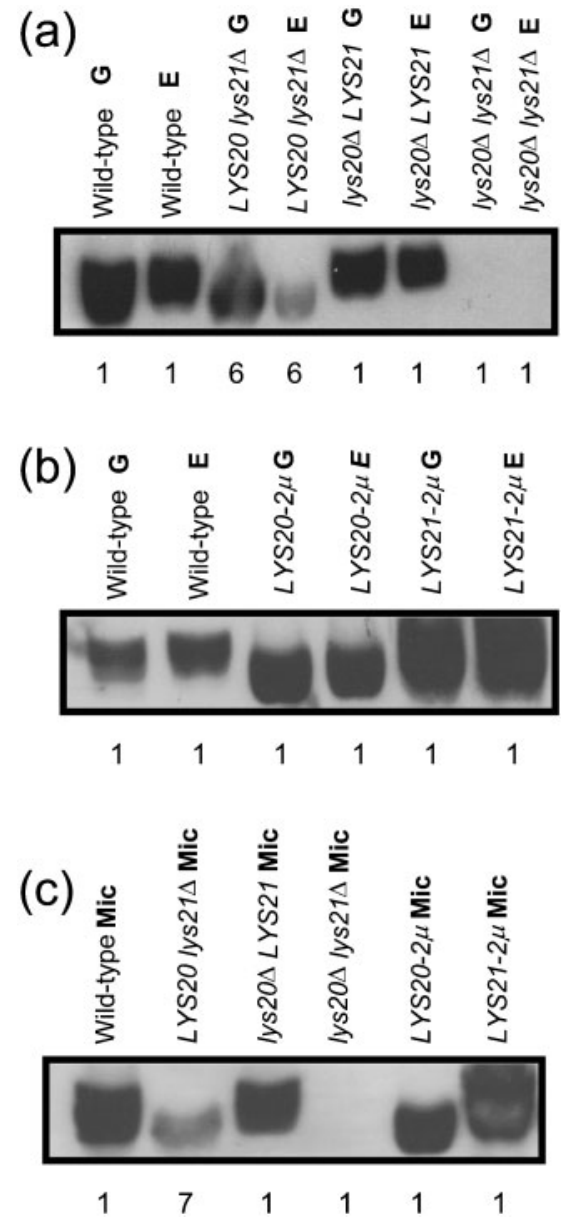

Fig. 3. Lys20p concentration is reduced under respiratory conditions. Cell-free extracts were prepared and subjected to immunoblot analysis using an anti-homocitrate synthase mAb. (a) Wild-type and mutant strains carrying single or double lys $20 \Delta$ or

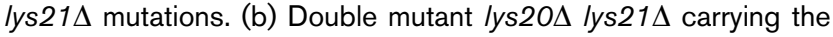
$2 \mu$ plasmid pRS426, harbouring either $L Y S 20$ or $L Y S 21$. In (a) and (b), cells were grown with shaking at 250 r.p.m. on either $2 \%$ glucose $(\mathrm{G})$ or $2 \%$ ethanol (E). (c) Strains were grown in static cultures with $2 \%$ glucose as the sole carbon source; Mic, microaerophilic conditions. Numbers represent the relative amount of total protein loaded in each lane; in panels (a) and (b) the number 1 corresponds to $30 \mu \mathrm{g}$ and in panel (c) to $15 \mu \mathrm{g}$. Lanes corresponding to the CLA1-2-20 strain ( LYS2O lys21A) were loaded with sixfold more total protein than the other lanes shown in panel (a) and sevenfold more total protein than the other lanes in panel (c). Strains used were: CLA1-2 (wild-type), CLA1-2-20

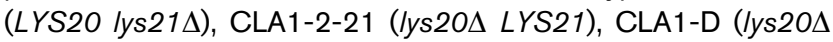
lys21A), CLA1-D-20M (LYS20-2 $\mu$ ) and CLA1-D-21M (LYS21$2 \mu)$.

detected for Lys $21 \mathrm{p}$ was found in extracts obtained from

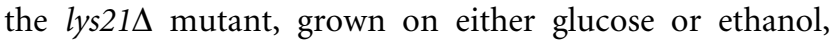
indicating that the Lys $20 \mathrm{p}$ concentration was lower than that of Lys $21 \mathrm{p}$; this was particularly evident in extracts obtained from ethanol-grown cells. Furthermore, extracts obtained from the glucose-grown wild-type strain showed a higher amount of antigen than those prepared from ethanol-grown cells, again showing that under these conditions Lys20p was less abundant than Lys21p. No signal was detected when extracts were prepared from the double mutant lys $20 \Delta$ lys $21 \Delta$. Immunoblotting of extracts

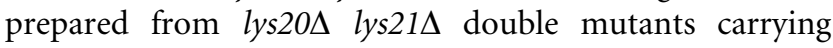
LYS20 or LYS21 on multicopy plasmids showed that a smaller amount of Lys20p was detectable under either fermentative or respiratory conditions than that found for Lys21p (Fig. 3b).

Since it has been shown elsewhere that homocitrate synthase from Schizosaccharomyces pombe is a labile target of oxidative stress (Kwon et al., 2006), we decided to analyse whether Lys20p post-transcriptional modification could be prevented under microaerophilic conditions. The various strains were grown as static cultures on MM with $2 \%$ glucose. As Fig. 3(c) shows, the amount of signal

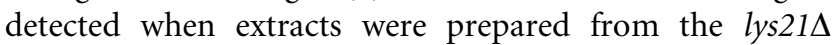
mutant was lower than those observed in extracts either from the wild-type strain or the lys200 mutant, even though a sevenfold higher amount of extract was used for the lys $21 \Delta$ mutant. A similar result was found for extracts

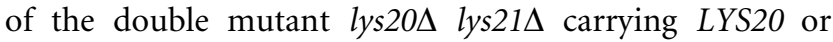
LYS21 on multicopy plasmids (Fig. 3c). These results show that Lys $20 \mathrm{p}$ concentration is negatively regulated by a posttranscriptional control that is more stringent when yeasts are grown on ethanol as carbon source and is independent of the aeration conditions. These results indicate that Lys20p has a higher capacity than Lys $21 p$ to synthesize lysine, since the lower homocitrate synthase activity detected in the presence of LYS20 on a multicopy plasmid allowed a threefold higher lysine accumulation, as compared with that found when LYS21 was carried on a multicopy plasmid (Fig. 1a, Table 3).

The results presented above suggest that Lys20p activity is controlled through mechanisms that constrain its capacity to biosynthesize lysine, and that under respiratory conditions Lys $21 \mathrm{p}$ is the predominant isoform. To better understand the properties of Lys $21 p$ that enable it to play a major role under respiratory conditions, we decided to analyse its kinetic properties.

\section{Lysine inhibition of Lys21p induces co-operativity towards $\alpha$-KG}

To obtain a stabilized Lys $21 \mathrm{p}$ preparation, crude extracts

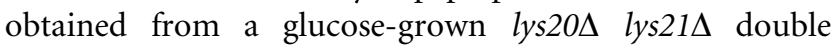
mutant harbouring LYS21 on a multicopy plasmid were filtered through a Superdex S-200 column; fractions showing homocitrate synthase activity were mixed with a trehalose solution to reach a $1 \mathrm{M}$ final concentration immediately after elution. Specific activity was increased fourfold, metabolites present in the crude extract were eliminated and Lys21p was eluted with proteins that did not interfere with the enzyme assay, since the pertinent controls did not show non-specific DCIP reduction. 
In the absence of lysine, the Lys $21 \mathrm{p}$ preparation displayed Michaelian kinetics, and the corresponding initial velocity patterns revealed that $K_{\mathrm{m} \alpha \text {-KG }}$ values were independent of AcCoA concentrations and vice versa (data not shown). This implies that $K_{\mathrm{m} \alpha-\mathrm{KG}}$ is a valid parameter, even if it was not obtained at saturating substrate concentration. The $K_{\mathrm{m}}$ values were $9.0 \pm 0.1$ and $0.019 \pm 0.002 \mathrm{mM}$ for $\alpha-\mathrm{KG}$ and AcCoA, respectively. These values were similar to those reported for the Lys20p isoform (Andi et al., 2005). The specific activity of a typical preparation was $1.50 \mu \mathrm{mol} \mathrm{h} \mathrm{h}^{-1} \mathrm{mg}^{-1}$. In order to compare these values with those displayed by the nonstabilized enzyme, assays were performed immediately after elution from the gel filtration column. For this preparation, the $K_{\mathrm{m}}$ values were $4.5 \mathrm{mM}$ for $\alpha-\mathrm{KG}$ and $0.017 \mathrm{mM}$ for AcCoA; specific activity was $1.4 \mu \mathrm{mol} \mathrm{h}^{-1} \mathrm{mg}^{-1}$.

Earlier work at other laboratories had indicated that Lys20p displays hyperbolic kinetics, that lysine behaves as a competitive inhibitor with respect to $\alpha$-KG binding, and that this isoform is less sensitive to lysine inhibition than Lys21p (Andi et al., 2004a, b, 2005; Feller et al., 1999). Using the above described preparation of Lys21p, it was found that the inhibitory effect of lysine, resulted in: (i) induction of positive co-operativity with respect to $\alpha-K G$ utilization; (ii) a decrease in $V_{\max }$, which reached a minimum value at saturating concentrations of lysine; and (iii) a reduction of Lys $21 \mathrm{p}$ affinity towards $\alpha-\mathrm{KG}$ (Fig. $4 \mathrm{a}, \mathrm{b})$. The observed co-operativity varied with lysine concentration, disappearing at zero and at saturating concentrations of this ligand; at both extremes the enzyme displayed hyperbolic kinetics. Co-operativity was maximal at $0.12 \mathrm{mM}$ lysine. The dependence of co-operativity upon lysine concentration was analysed by fitting the kinetic data to the Hill equation (Segel, 1975) and by plotting the corresponding Hill coefficients as a function of the log of inhibitor concentration (Fig. 4b). This semi-log plot shows the characteristic bell-shaped curve of a typical allosteric inhibitor. The $K_{\mathrm{i}}$ of allosteric inhibition for Lys $21 \mathrm{p}$ was $0.053 \mathrm{mM}$, which is 10 -fold lower than that reported for Lys20p competitive inhibition (Andi et al., 2005). This value was calculated using the Monod, Wyman and Changeux symmetry model considering a mixed $K$ and $V$ system in which the inhibitor binds exclusively to the $\mathrm{T}$ state of the enzyme (Monod et al., 1965).

The observed co-operativity could not be attributed to other components of the Lys $21 \mathrm{p}$ stabilized preparation that was used for the kinetic studies, since it was only induced when lysine was added. When the AcCoA concentration was varied in the presence of lysine, Lys $21 \mathrm{p}$ displayed Michaelian kinetics, and both $V_{\max }$ and $K_{\mathrm{m}}$ AcCoA were reduced (data not shown). Modulation of homocitrate synthase activity by AcCoA is not likely to occur in vivo, since the intracellular concentration of this substrate is considered to be at saturation (Andi et al., 2005). The fact that the $\alpha-K G$ intracellular concentration is similar to the $K_{\mathrm{m}} \alpha$-KG for both Lys20p (Andi et al., 2005) and Lys21p suggests that this substrate and not AcCoA modulates the catalytic activity of these enzymes.

The results presented above indicate that despite their high sequence identity, homocitrate synthase isozymes show significant differences in their kinetic behaviour, which could result in a differential response to the concentration of substrates in vivo, and thus in distinct physiological roles. The low lysine sensitivity of Lys20p allows high homocitrate production, whereas the high lysine sensitivity and induced co-operativity of Lys $21 \mathrm{p}$ allow this isoform to balance $\alpha$-KG utilization for lysine biosynthesis and other metabolic processes.

In order to analyse whether increased lysine biosynthesis could have detrimental effects, growth rate and metabolite intracellular concentration were determined in strains overexpressing either LYS20 or LYS21.
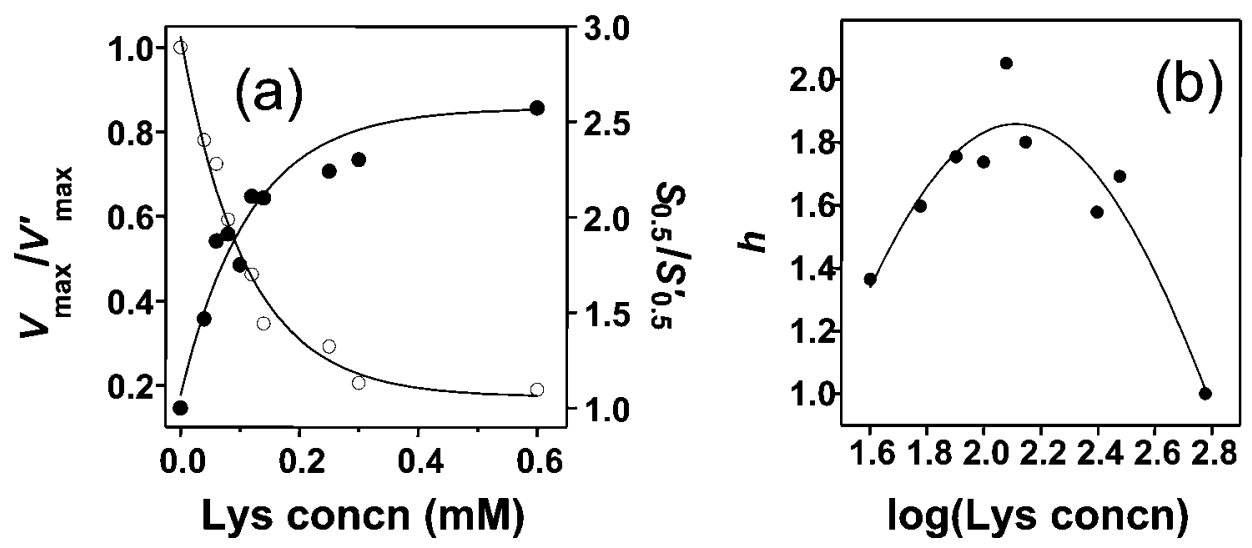

Fig. 4. Effect of lysine on the kinetic parameters of Lys21p. In (a) and (b), the experimental data were fitted to the Hill equation and the resulting parameters were plotted as a function of lysine concentration. (a) Graph of the normalized apparent $V_{\text {max }}$ values $(\bigcirc)$ and $S_{0.5}(\bullet)$ as a function of lysine concentration. $V_{\max }^{\prime}$ and $S_{0.5}^{\prime}$ are the values obtained in the absence of lysine. (b) Plot of the Hill coefficient $(h)$ values versus log of lysine concentration (in $\mu \mathrm{M}$ ). 


\section{Overexpression of either LYS20 or LYS21 decreases the growth rate under respiratory conditions}

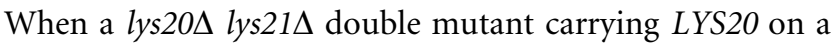
multicopy plasmid was grown on either glucose or ethanol, it accumulated a 10-fold higher lysine pool than that of the wild-type strain, and threefold higher than that displayed by the double mutant carrying LYS21 on a multicopy plasmid (Fig. 1a). As Table 2 shows, high lysine accumulation is accompanied by a diminution of growth rate on ethanol, while this effect was not observed with glucose as the carbon source. These results suggest that high lysine biosynthesis could result in a decreased growth rate when ethanol is provided as the carbon source, probably due to unbalanced utilization of tricarboxylic cycle intermediates. Determination of $\alpha$-KG pools showed that the wild-type strain and single mutants displayed an equivalent $\alpha-\mathrm{KG}$ pool when grown on either glucose or ethanol, since these strains did not overproduce lysine. However, strains carrying LYS20 or LYS21 on a multicopy plasmid showed a higher $\alpha-K G$ pool than the wild-type strain when these were grown on glucose (Fig. 1b). This suggests that increased lysine biosynthesis and its consequent accumulation in the vacuole could operate as a driving force, increasing production of metabolites from glucose to $\alpha-\mathrm{KG}$ with a concomitant increase the $\alpha-\mathrm{KG}$ pool (Fig. 1a, b). This was more evident when LYS20 was overexpressed, confirming that Lys20p had a higher capacity to synthesize lysine than Lys 21 p. In the presence of ethanol as carbon source, the $\alpha-K G$ pool detected in strains carrying either LYS20 or LYS21 on multicopy plasmids showed a very slight increment as compared with the wild-type, suggesting that flux of intermediates through the $\alpha$-KG-producing pathways cannot be increased further. Nonetheless, lysine pools show similar levels to those found on glucose. It could thus be considered that under respiratory conditions, overexpression of either LYS20 or LYS21 could result in a metabolic imbalance, affecting growth rate. This effect was abolished after addition of lysine to the media (Table 2), suggesting that lysine counteracts the above-described phenotype by repressing expression of the paralogous genes or by directly inhibiting the isozymes.

\section{DISCUSSION}

This study addresses the question of whether Lys20p and Lys21p play overlapping or distinct physiological roles and whether these roles are involved in the inherent capacity of $S$. cerevisiae to grow under fermentative and respiratory conditions. Results presented in this paper show: (i) that lysine is a strong inhibitor of Lys21p and induces cooperativity towards $\alpha-\mathrm{KG}$; (ii) that Lys $21 \mathrm{p}$ is needed to sustain wild-type growth under respiratory conditions; and (iii) that Lys20p has a higher capacity to synthesize lysine, and its intracellular concentration is reduced under respiratory conditions.

\section{Under fermentative conditions, LYS20- and LYS21-encoded enzymes play redundant roles}

Under fermentative conditions, single mutants devoid of Lys20p or Lys21p produce a lysine pool which is approximately half that detected in the wild-type strain, however, wild-type growth is supported by any of these mutant strains. Even when LYS21 and LYS20 are overexpressed in glucose and lysine pools, respectively, four to tenfold, the growth rate is not reduced; the selective use of $\alpha-\mathrm{KG}$ for lysine biosynthesis appears not to be critical for growth under fermentative conditions. These results are in agreement with previous observations that $\alpha-\mathrm{KG}$ drainage to glutamate biosynthesis is not deleterious to fermentative growth (DeLuna et al., 2001). Thus under fermentative conditions, LYS20 and LYS21 play redundant roles and the simultaneous activity of both Lys20p and Lys21p has an additive effect, which is required to attain wild-type lysine pools.

S. cerevisiae is unable to utilize lysine as a nitrogen or carbon source (Watson, 1976); thus, it could be considered that this amino acid plays a distinct metabolic role. In this regard, evidence has begun to appear that suggests that lysine contributes to the build-up of the stress response due to $\mathrm{H}_{2} \mathrm{O}_{2}$ treatment (Stephen \& Jamieson, 1997) or to the prevention of the apoptotic response provoked by amino acid starvation (Eisler et al., 2004). These considerations are further supported by the fact that LYS20 and LYS21 expression is equivalent in glucose-grown cells, in contrast to what happens with the duplicate pair GDH1 and GDH3, whereby expression of $\mathrm{GDH} 3$ is completely repressed under fermentative conditions (Avendaño et al., 2005; DeLuna et al., 2001). It would thus seem that the evolution of the regulatory system that determines LYS20 and LYS21 transcriptional regulation has maintained the expression of both genes, which probably means that high lysine biosynthesis takes precedence if cells are exposed to particular stressful conditions.

\section{Biochemical specialization of Lys20p and Lys21p results in distinct kinetic properties, which are critical to sustaining wild-type growth under respiratory conditions}

Kinetic characterization of Lys $21 \mathrm{p}$ showed that its activity is strongly inhibited by lysine, which in addition induces cooperativity for $\alpha-K G$ binding. The fact that Yarrowia lipolytica homocitrate synthase has also been found to display a cooperative kinetic behaviour similar to the one described herein for Lys21p (Gaillardin et al., 1976) is worthy of mention. Conversely, LYS20-encoded homocitrate synthase does not display co-operative kinetics and is much less sensitive to lysine inhibition (Andi et al., 2005). Hence, differential lysine sensitivity and induced co-operativity of Lys20p and Lys21p constitute key mechanisms modulating homocitrate synthase activity and thus lysine biosynthesis.

The kinetic behaviour of Lys21p is particularly relevant to sustaining respiratory metabolism. Single mutants devoid 
of Lys $21 \mathrm{p}$ show reduced growth on ethanol, while lys $20 \Delta$ mutants grow as well as the wild-type. In addition, Lys $20 \mathrm{p}$ activity is threefold lower than that displayed by Lys21p. Therefore, Lys20p is unable to compensate for a lack of LYS21, revealing a key role for Lys $21 \mathrm{p}$ under nonfermentative conditions. Under fermentative or respiratory conditions, both Lys20p and Lys $21 p$ enzymic activities are needed to achieve wild-type lysine pools. Increased LYS2O expression in ethanol-grown cultures could constitute an element counterbalancing Lys20p inactivation, assuring the presence of a certain amount of biologically active Lys $20 \mathrm{p}$, again emphasizing the fact that high lysine synthesis must be maintained, although only to a certain level, since excessive homocitrate synthase activity during respiratory growth is deleterious. When LYS21 or LYS20 is overexpressed, regulatory mechanisms restraining Lys $20 \mathrm{p}$ and Lys $21 \mathrm{p}$ activities are overwhelmed; thus, lysine is overproduced, although $\alpha$-KG pools remain nearly equivalent to those found in the wild-type strain. This suggests that $\alpha$ KG producing pathways are near their maximum capacity, and that uncontrolled lysine biosynthesis and its further transport into the vacuole could enhance the flow of intermediates from ethanol to lysine, limiting the amount of $\alpha-K G$ available to other pathways. In this regard it has been shown that specialization of the NADP-dependent glutamate dehydrogenases Gdh1p and Gdh3p results in a more relaxed distribution of $\alpha-K G$ to either glutamate biosynthesis or energy-yielding metabolism when cells are grown on a non-fermentable or limiting carbon source (DeLuna et al., 2001).

Earlier studies have led to the proposition that Lys20p is responsible for most of the lysine produced under fermentative metabolism, while Lys $21 \mathrm{p}$ is only important under extreme lysine limitation (Feller et al., 1999). This is supported by the fact that LYS20 disruption resulted in a $75 \%$ diminution of the intracellular lysine pool, as compared with the wild-type strain, and a concomitant decrease in enzymic activity, while a lys $21 \Delta$ mutant showed lysine levels equivalent to those found in the wild-type strain. In addition, the fact that Lys $21 \mathrm{p}$ was severely inhibited by lysine further supports a role for Lys $21 \mathrm{p}$ under lysine limitation only. Our results agree with those reported by Feller et al. (1999) in the sense that strains that lack either LYS20 or LYS21 show a wild-type growth phenotype under fermentative conditions; however, the additive effect, reflected in lysine accumulation and homocitrate synthase enzymic activity, does not seem to be possible in the genetic background used by Feller et al. (1999). It could thus be considered that the particular strain used by those authors does not have the posttranscriptional regulatory system of our strain, and thus in this genetic background, Lys20p has no constraints and develops full activity. Feller et al. (1999) did not address the role of these enzymes under respiratory conditions; thus, it is not possible to definitively conclude whether the Lys $20 \mathrm{p}$ post-transcriptional regulation herein described is absent in that particular genetic background. There are various examples to document the fact that genetic background can result in striking physiological differences. Most outstanding have been the results obtained by Tate et al. (2006), which show that the role of Sit $4 \mathrm{p}$ in the nuclear localization of the GLN3-encoded transcriptional activator is straindependent.

\section{Concluding remarks}

Genetic redundancy is a major feature of virtually all species; duplication of functional genes constitutes a source of new or specialized functions of the proteins. Duplicate genes that are retained either provide an increased dosage of the same product or go through a process of subfunctionalization, during which both copies of the gene lose a subset of their ancestral functions, while acquiring new properties (Force et al., 1999; Lynch \& Force, 2000). A similar example in amino acid biosynthesis is the specialization of the GDH1- and GDH3-encoded NADPdependent glutamate dehydrogenases, whereby both genes are required for glutamate biosynthesis under fermentative and respiratory growth. For GDH1 and GDH3, simultaneous changes in the kinetic properties and transcriptional regulation of both enzymes have resulted in a regulatory mechanism that supports facultative metabolism (Avendaño et al., 2005; Deluna et al., 2001). Nonetheless, the case of LYS20 and LYS21 offers interesting differences compared with that of the glutamate biosynthesis isozymes. The analysis of LYS20 and LYS21 indicates that for growth under fermentative metabolism, both genes have been retained to increase gene dosage, meaning that the additive effect of both genes is needed to attain wildtype lysine pools. However, Lys $21 \mathrm{p}-\mathrm{Lys} 20 \mathrm{p}$ diversification is essential for respiratory metabolism; here the amount and activity of Lys20p are strictly controlled to avoid increased carbon flux being channelled to produce lysine (Fig. 5). Under these conditions, Lys21p plays a determining role and can sustain wild-type growth by itself. It is noteworthy that both LYS20 and LYS21 are expressed under fermentative and respiratory conditions; thus, the evolution of the cis-acting elements has not led, as might be expected, to complete LYS20 repression, again suggesting that the expression of this gene is required to allow high lysine pools.

This study confirms that nitrogen and carbon metabolism are co-ordinately modulated and that the genetic and metabolic regulation of the genes involved in nitrogen metabolism can be influenced by the nature of the carbon source. The diversification of Lys $20 \mathrm{p}$ and Lys $21 \mathrm{p}$ described adds to the growing list of yeast isozymes whose function has undergone modifications that enable facultative metabolism.

\section{ACKNOWLEDGEMENTS}

The authors are grateful to L. Ongay, G. Codiz and M. Sosa [Unidad de Biología Molecular, Instituto de Fisiología Celular, Universidad 
(a) Glucose

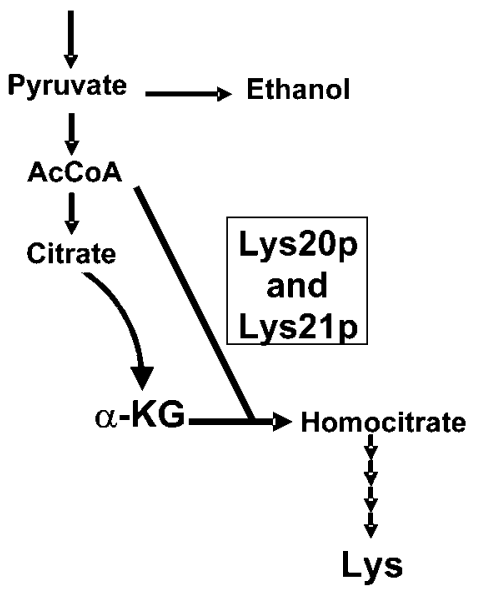

(b)

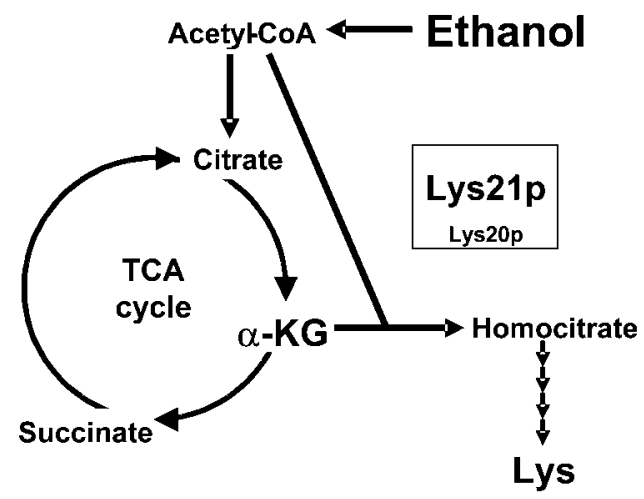

Fig. 5. Model depicting the importance of Lys20p or Lys21p for fermentative and respiratory growth. (a) During growth on glucose, homocitrate is produced by Lys20p and Lys $21 \mathrm{p}$; the Lys $20 \mathrm{p}$ contribution is higher than under respiratory conditions. (b) During growth with ethanol as the carbon source, homocitrate is produced mainly by Lys $21 \mathrm{p}$; its strong lysine inhibition and co-operative properties allow this isoform to balance the use of $\alpha$-KG for lysine biosynthesis and energy-yielding metabolism.

Nacional Autónoma de México (UNAM)] for DNA sequencing and synthesis of oligonucleotides; to A. Lucumi-Moreno for help during Lys $21 \mathrm{p}$ partial purification; and to Z. Savedra, P. Salazar, A. M. Estrada and G. X. Ayala for their help during amino acid determinations. We are indebted to D. González-Halphen for helpful discussions and critical review of the manuscript. This work was supported in part by the Dirección de Asuntos del Personal Académico, UNAM grant IN210706-3, by Consejo Nacional de Ciencia y Tecnología grant 49970 and by the Macroproyecto de Tecnologías de la Información y la Computación, UNAM. H. Q. is the recipient of CONACYT fellowship 167247 and a grant (PAEPDoctoral) from the Dirección General de Posgrado, UNAM.

\section{REFERENCES}

Andi, B., West, A. H. \& Cook, P. F. (2004a). Kinetic mechanism of histidine-tagged homocitrate synthase from Saccharomyces cerevisiae. Biochemistry 43, 11790-11795.

Andi, B., West, A. H. \& Cook, P. F. (2004b). Stabilization and characterization of histidine-tagged homocitrate synthase from Saccharomyces cerevisiae. Arch Biochem Biophys 421, 243-254.

Andi, B., West, A. H. \& Cook, P. F. (2005). Regulatory mechanism of histidine-tagged homocitrate synthase from Saccharomyces cerevisiae. I. Kinetic studies. J Biol Chem 280, 31624-31632.

Avendaño, A., Riego, L., DeLuna, A., Aranda, C., Romero, G., Ishida, C., Vázquez-Acevedo, M., Rodarte, B., Recillas-Targa, F. \& other authors (2005). Swi/SNF-GCN5-dependent chromatin remodelling determines induced expression of $G D H 3$, one of the paralogous genes responsible for ammonium assimilation and glutamate biosynthesis in Saccharomyces cerevisiae. Mol Microbiol 57, 291-305.

Betterton, H., Fjellstedt, T., Matsuda, M., Ogur, M. \& Tate, R. (1968). Localization of the homocitrate pathway. Biochim Biophys Acta 170, 459-461.

Chen, J. C. Y. \& Powers, T. (2006). Coordinate regulation of multiple and distinct biosynthetic pathways by TOR and PKA kinases in $S$. cerevisiae. Curr Genet 49, 281-293.
Chen, S., Brockenbrough, J. S., Dove, J. E. \& Aris, J. P. (1997). Homocitrate synthase is located in the nucleus in the yeast Saccharomyces cerevisiae. J Biol Chem 272, 10839-10846.

Christianson, T. W., Sikorski, R. S., Dante, M., Shero, J. H. \& Hieter, P. (1992). Multifunctional yeast high-copy-number shuttle vectors. Gene 110, 119-122.

DeLuna, A., Avendaño, A., Riego, L. \& González, A. (2001). NADPglutamate dehydrogenase isoenzymes of Saccharomyces cerevisiae. Purification, kinetic properties, and physiological roles. J Biol Chem 276, 43775-43783.

Eisler, H., Frohlich, K. \& Heidenreich, E. (2004). Starvation for an essential amino acid induces apoptosis and oxidative stress in yeast. Exp Cell Res 300, 345-353.

Feller, A., Dubois, E., Ramos, F. \& Pierard, A. (1994). Repression of the genes for lysine biosynthesis in Saccharomyces cerevisiae is caused by limitation of Lys14-dependent transcriptional activation. Mol Cell Biol 14, 6411-6418.

Feller, A., Ramos, F., Pierard, A. \& Dubois, E. (1999). In Saccharomyces cerevisiae, feedback inhibition of homocitrate synthase isoenzymes by lysine modulates the activation of LYS gene expression by Lys14p. Eur J Biochem 261, 163-170.

Force, A., Lynch, M., Pickett, F. B., Amores, A., Yan, Y. L. \& Postlethwait, J. (1999). Preservation of duplicate genes by complementary, degenerative mutations. Genetics 151, 1531-1545.

Gaillardin, C. M., Poirier, L. \& Heslot, H. (1976). A kinetic study of homocitrate synthetase activity in the yeast Saccharomycopsis lipolytica. Biochim Biophys Acta 422, 390-406.

González, B., Francois, J. \& Renaud, M. (1997). A rapid and reliable method for metabolite extraction in yeast using boiling buffered ethanol. Yeast 13, 1347-1356.

Ito, H., Fukuda, Y., Murata, K. \& Kimura, A. (1983). Transformation of intact yeast cells treated with alkali cations. J Bacteriol 153, 163168.

Kosuge, T. \& Hoshino, T. (1998). Lysine is synthesized through the $\alpha$ aminoadipate pathway in Thermus thermophilus. FEMS Microbiol Lett 169, 361-367. 
Kwon, E. S., Jeong, J. H. \& Roe, J. H. (2006). Inactivation of homocitrate synthase causes lysine auxotrophy in copper/zinccontaining superoxide dismutase-deficient yeast Schizosaccharomyces pombe. J Biol Chem 281, 1345-1351.

Lowry, O. H., Rosebrough, N. J., Farr, A. L. \& Randall, R. J. (1951). Protein measurement with the Folin phenol reagent. J Biol Chem 193 265-275.

Lynch, M. \& Force, A. (2000). The probability of duplicate gene preservation by subfunctionalization. Genetics 154, 459-473.

Merico, A., Sulo, P., Piskur, J. \& Compagno, C. (2007). Fermentative lifestyle in yeasts belonging to the Saccharomyces complex. FEBS J 274, 976-989.

Monod, J., Wyman, J. \& Changeux, J. P. (1965). On the nature of allosteric transitions: a plausible model. J Mol Biol 12, 88-118.

Natarajan, K., Meyer, M. R., Jackson, B. M., Slade, D., Roberts, C., Hinnebusch, A. G. \& Marton, M. J. (2001). Transcriptional profiling shows that Gcn $4 p$ is a master regulator of gene expression during amino acid starvation in yeast. Mol Cell Biol 21, 4347-4368.

Nishida, H. \& Nishiyama, M. (2000). What is characteristic of fungal lysine synthesis through the $\alpha$-aminoadipate pathway? J Mol Evol 51, 299-302.

Nishida, H., Nishiyama, M., Kobashi, N., Kosuge, T., Hoshino, T. \& Yamane, H. (1999). A prokaryotic gene cluster involved in synthesis of lysine through the amino adipate pathway: a key to the evolution of amino acid biosynthesis. Genome Res 9, 1175-1183.

Piskur, J. (2001). Origin of the duplicated regions in the yeast genomes. Trends Genet 17, 302-303.

Ramos, F. \& Wiame, J. M. (1985). Mutation affecting the specific regulatory control of lysine biosynthetic enzymes in Saccharomyces cerevisiae. Mol Gen Genet 200, 291-294.

Ramos, F., Dubois, E. \& Pierard, A. (1988). Control of enzyme synthesis in the lysine biosynthetic pathway of Saccharomyces cerevisiae. Evidence for a regulatory role of gene LYS14. Eur J Biochem 171, 171-176.

Sambrook, J., Fritsch, E. F. \& Maniatis, T. (1989). Molecular Cloning: a Laboratory Manual, 2nd edn. Cold Spring Harbor, NY: Cold Spring Harbor Laboratory.
Segel, I. H. (1975). Enzyme Kinetics: Behavior and Analysis of Rapid Equilibrium and Steady State Enzyme Systems, pp. 346-462. New York: Wiley.

Sikorski, R. S. \& Hieter, P. (1989). A system of shuttle vectors and yeast host strains designed for efficient manipulation of DNA in Saccharomyces cerevisiae. Genetics 122, 19-27.

Stephen, D. W. S. \& Jamieson, D. J. (1997). Amino acid-dependent regulation of the Saccharomyces cerevisiae GSH1 gene by hydrogen peroxide. Mol Microbiol 23, 203-210.

Struhl, K. \& Davis, R. W. (1981). Transcription of the his3 gene region in Saccharomyces cerevisiae. J Mol Biol 152, 535-552.

Takagi, H., Iwamoto, F. \& Nakamori, S. (1997). Isolation of freezetolerant laboratory strains of Saccharomyces cerevisiae from prolineanalogue-resistant mutants. Appl Microbiol Biotechnol 47, 405-411.

Tate, J. J., Feller, A., Dubois, E. \& Cooper, T. G. (2006). Saccharomyces cerevisiae Sit4 phosphatase is active irrespective of the nitrogen source provided, and Gln3 phosphorylation levels become nitrogen sourceresponsive in a sit4-deleted strain. J Biol Chem 281, 37980-37992.

Towbin, H., Staehelin, T. \& Gordon, J. (1979). Electrophoretic transfer of proteins from polyacrylamide gels to nitrocellulose sheets: procedure and some applications. Proc Natl Acad Sci U S A 76, 4350-4354.

Valenzuela, L., Aranda, C. \& González, A. (2001). TOR modulates GCN4-dependent expression of genes turned on by nitrogen limitation. J Bacteriol 183, 2331-2334.

Watson, T. G. (1976). Amino-acid pool composition of Saccharomyces cerevisiae as a function of growth rate and amino-acid nitrogen source. J Gen Microbiol 96, 263-268.

Wolfe, K. H. \& Shields, D. C. (1997). Molecular evidence for an ancient duplication of the entire yeast genome. Nature 387, 708-713.

Xu, H., Andi, B., Qian, J., West, A. H. \& Cook, P. F. (2006). The $\alpha-$ aminoadipate pathway for lysine biosynthesis in fungi. Cell Biochem Biophys 46, 43-64.

Edited by: M. Tien 